\title{
Design collaborations: the good, the bad and the unthinkable
}

\begin{abstract}
This conceptual paper is a study of the impact of three drivers: collaboration, interdisciplinary practice and co-operation. These were taken as a starting point for a change process, resulting in radical new design-learning environments situated within Manchester School of Art, at the Manchester Metropolitan University, UK. We recognise that these drivers will be the new imperative for future design practitioners.
\end{abstract}

Contextually, seeing national and international shifts in design and the perceived value of a design education today we challenged the idea of single 'mono' design courses and questioned our own validity.

Subsequently, we undertook a fundamental re-think of what an Art school is for. By taking the notion of interdisciplinary design education this resulted in new curricula, a re-branding of the Manchester School of Art and a physical resource to match our ambition. This paper articulates the design process employed in engaging staff to reflect and re-focus on the essence of an art school, and through doing this, develop a collegiate approach to the re-design of our buildings, a coming together of our distinct departments under a coherent brand, and the embedding of pedagogical collaboration through curricula in the form of the experimental Unit X.

Keywords: collaboration, interdisciplinary, co-operation 


\section{STARTING POINTS}

\subsection{INTER-DISCIPLINARY PRACTICE}

Through our internal observations and external international engagement within the design world, we were seeing that fundamentally design industry practice is set within multi-disciplinary practice, where inter-disciplinary teamwork, collaboration and adaptability are vital skills that need to be fostered. As boundaries between disciplines, which were once thought of as distinct become increasingly blurred, there is a need to prepare students for the new realities in industry, allowing for an inter-disciplinary approach. We also recognised that this takes place through the orchestration of a mix of disciplines and recognizing that the most creative solutions come from the mix or the spaces in between the disciplines and that creativity is not innate, you have to work at it.

Insightful reports in the U.K. on the nature of design enabled us to further contextualise what we wanted to achieve. The Design Commission's astute report 'Restarting Britain, Design Education and Growth' recognized that:

'as the knowledge base advances, innovations have increasingly come from multi disciplinary teams rather than lone operators. Steve Jobs, Jonathan Ive and the management philosophy of Apple is probably the most revered $21^{\text {st }}$ century example of the interdisciplinary team' (Design Commission, 2011).

We were also struck by changes in the idea of design as it moves to a 'process' and 'enabler' to improve and enhance our lives. Design is increasingly an active 'social' tool rather than simply a problem solved. Focus is placed upon the importance of design socially, culturally, economically and how it can regenerate and enhance our lives.

\subsection{SOFT TRANSFERABLE SKILLS}

To activate this way of working and encourage this type of design thinking we felt that they needed educationally to be further embedded. It became clear that skills in collaboration and co-operation needed prioritising for student development. Significantly, the often subjugated 'soft' transferable skills of project management, negotiation and teamwork, which are sought after skills for our graduates needed to be brought to the fore and made explicit.

\subsection{THE QUESTION OF DESIGN AND ITS VALUE}

If you consider the word Design it is both a noun and a verb. On reflection we have chosen to place a much greater emphasis of design as verb. Increasingly what becomes attractive then is not the result of something i.e. a final plan (noun) but how the plan is created (verb), therefore how design increasingly becomes an proactive enabler and not simply about the end product.

By citing examples such as 'DIY lab' in Berlin and social design as seen at the Design Academy, Eindhoven, they became for us useful counterpoints to consider. Contextually, staff also visited a number of institutes internationally in order to understand the education and design trends that were taking place. This included visits to China, Hong Kong, India, and in 2011 the Design department took part in the 'World 100 Design Schools' Taipei Expo as part of a number of celebrations at Icograda. The expo and Icograda itself allowed us to reflect further on this subject 
with conference themes of sustainability, social issues and ageing population, all re-inforcing the need for design practice to be an active enabler.

We could see that Design is re-framing itself and becoming more confident in where it can go. A good example of this was at the design symposium in Amsterdam in 2010, entitled 'I don't know where I'm going but I want to be there'. This addressed the expanding field of Graphic Design and the changes that are taking place within this field. It states:

'What used to be a culturally defined, craftsmanship based profession has evolved into a popular, democratized discipline permeating all types of media. Todays visual communication landscape functions as a breeding ground for both text and image, which are produced and consumed simultaneously in networked loops. Contemporary practitioners generate their own context and rules, and navigate the world through an array of sampled media, methods, styles, and ideas. No one knows where graphic design is going, or what it will be called tomorrow. What we do know is that it's on the move.'

Interestingly, adding to this change of design as verb, Schleicher, introduces further the idea of 'versatilitists'.

'people who can respond creatively to new challenges and situations'...'The knowledge world is no longer divided between specialists and generalists. A new group-let's call them "versatilists" - has emerged. They apply depth of skill to a progressively widening scope of situations and experiences, gaining new competencies, building relationships and assuming new roles. They are capable not only of constantly adapting, but also constantly learning and growing in a fastchanging world'. (Design Commission, 2011)

\section{QUESTIONING THE NORM}

If we now understand that design is changing and that students need to respond to 'new challenges and situations' then in a constructively critical pedagogic environment, student learning should be about dealing with uncertainty, the unknowing and dealing with meaning set within the complexity of our respective worlds. However, educators can find this adaptability challenging as we have become institutionalised in our ways of doing and thinking.

What this meant for our staff base, brought up on predominantly a diet of Eurocentric Bauhaus, Hofmann methodologies of education was that we were entering new territories and questioning these norms. What also becomes apparent is what constitutes an academic's role is also questioned. We needed to support our staff to develop the skill base required and so we started to cultivate the idea of pedagogic designers.

\subsection{INTERVENTIONISTS, BEING PEDAGOGIC DESIGNERS}

A great deal of design education struggles to see how we can positively make the bridge between our commercial 'professional' design practice and how this relates to a pedagogic practice. As design academics we have an 'idea' of what makes a design education that has been shaped by our professional experiences, however educationally, being a pedagogue and a designer are traditionally seen as two separate roles or inputs. We can even go as far as to say that pedagogy is secondary to what we teach as designers. Therefore, we recognised a need to 
create an environment to explore the language and actions of pedagogy 'through' design - we can call this pedagogic design. We cultivated the connection between being a designer and educator by marrying this with being a pedagogic designer. As 'designers' we interpret information, play with semantics and give form, and are problem solvers. These skills and experiences need to be brought to the front and translated in our role also as educators whilst developing interactive experiences for our students. The role of pedagogic designers will increasingly become vital as we move from information givers to facilitators and explore other forms of pedagogic delivery that are relevant to design. We will progressively become more like active interventionists and explorers with our students in the learning space.

Theoretically, this concept of navigation and inquiry and the development of cognitive skills is encouraged by Schleicher in 'The case for $21^{\text {st }}$ century learning. He points out:

'Education today is much more about ways of thinking which involve creative and critical approaches to problem-solving and decision-making. It is also about ways of working, including communication and collaboration, as well as the tools they require, such as the capacity to recognise and exploit the potential of new technologies, or indeed, to avert their risks. And last but not least, education is about the capacity to live in a multi-faceted world as an active and engaged citizen. These citizens influence what they want to learn and how they want to learn it, and it is this that shapes the role of educators. ' (Schleicher 2010)

\section{OLD SCHOOL, NEW SCHOOL, ART SCHOOL}

In order to move forward on this work we undertook a fundamental re-think of what an Art school is for. This took in three aspects.

Our initial task was re-branding the school's identity, this is set within a backdrop where the Manchester School of Design was founded in 1838. We responded to our heritage and re-visited its original ethos and values of 'supporting the creative economy of the region' set within the context of the now. With this came our mission statement:

'Manchester School of Art believes an art school is more than just a place. An art school is a community and a laboratory. Our business is to encourage creative risk taking, to question boundaries and challenge the conventional. Art school is a place where language is extended and dialogue developed. Art school is a bridge between the acceptable, and the possible, between what is and what if.'

and with it our acknowledgement of both our heritage and ambition. 

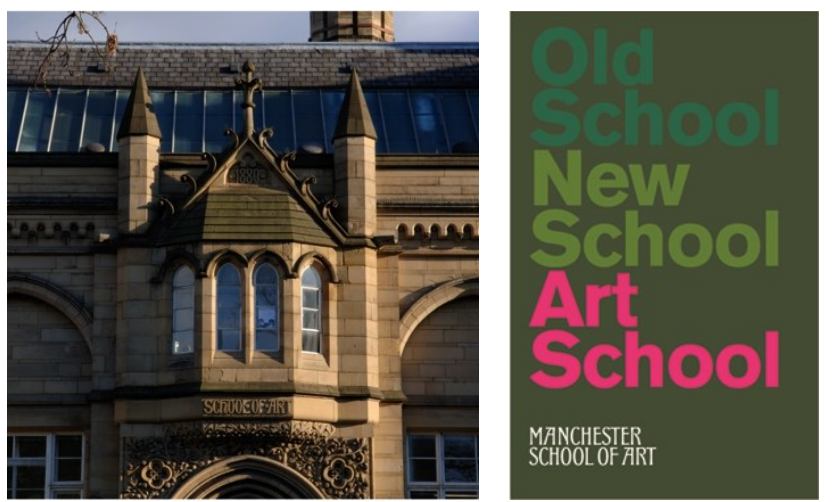

Figure 1: School of Art 1880 entrance

Figure 2: Old School, New School, Art School re-brand document

In order to meet the aspirations of the brand we also worked on a new $£ 35$ million Art School's building programme. Designed in partnership and in collaboration with architects Fielden Clegg Bradley, the new Design Studios attached to the existing Art School have become our front door.

The open 'village green' interior spaces, with their interlinked studio floors, shared study spaces surrounded by workshops and teaching rooms provide a communal studio environment designed to foster the sharing of practice and co learning. Boundaries are deliberately blurred and territory is fluid.
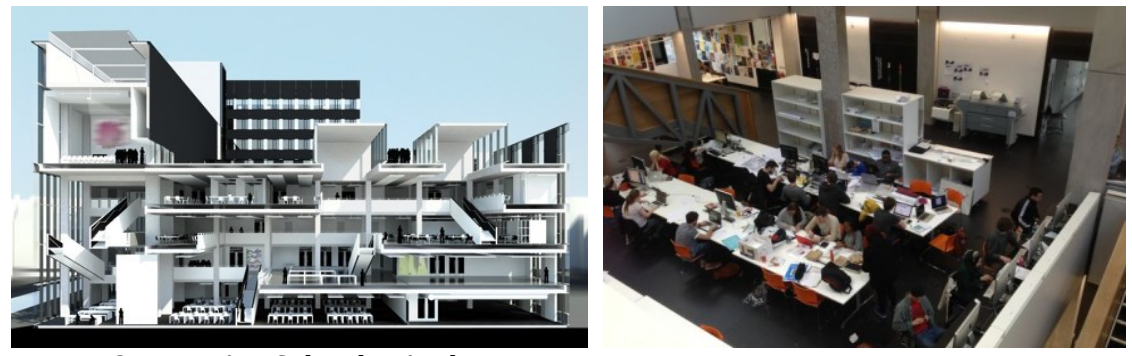

Figure 3: New Art School - Architects vision

Figure 4: Village Green studio spaces in use

The environment determinedly reflects the ambition inherent within our initial debates and analysis.

When asked to consider what an art school should look like staff drawings demonstrated the value placed on the intersections, the 'interplay' and dialogue across the boundaries of programmes. These influential discussions have helped form the architects' brief and ultimately our new environment. 


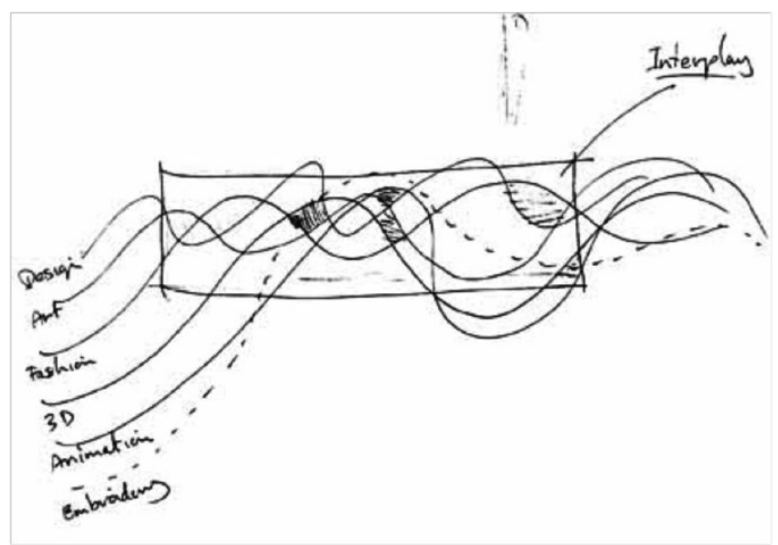

Figure 5: Staff diagram highlighting idea of 'Interplay'

The third aspect was to create radical new curricula, which highlighted the new realties of design. One example being the radical Unit X.

\section{UNIT X CASE STUDY}

And so to Unit X, our case study. A pedagogic exploration that has the ambition to encapsulate the three identified key drivers of collaboration, interdisciplinary practice and co-operation and places our staff in the pivotal role as pedagogic designers.

\subsection{WHAT IS UNIT X?}

Unit $X$ is a 10 week fully assessed 30 credit-bearing unit of study which is being rolled out over three years of undergraduate study. The unit brings students together working in cross programme collaborative teams, tackling externally focused projects and engaging with external partners. Now in it's third year it has a cohort about to begin the final level and in Spring 2014 we will see three year groups working in this new model across the entire School for the first time, and involving upwards of 2,000 students.

By encouraging an inter-disciplinary environment the tension between subject specificity and fostering an environment of cross-subject pollination is heightened and tested. Initial concerns raised by the staff team included anxiety over the diminishing of skills unique to subject areas; the pedagogic mapping of their 'subject' curricula and how this co-exists with cross-school curricula; the loss of subject control and ownership and the risk associated with letting go of subject specificity and finally allowing students to own the direction of learning.

The biggest challenge therefore centered on collaboration. The notion was debated in subject areas ie. is fine art a collaborative practice, is animation, is photography? Asking staff to collaborate with colleagues with different specialisms and respective norms of practice further tested this. In undertaking Unit $X$ we have turned the spotlight on the question and highlighted how being collaborative is a real skill in itself.

\subsection{THE ORIGINS OF UNIT X: DEVELOPING CAPACITY}


Crucial to the development of our expertise and confidence as academics in tackling the collaboration, co-operation challenge, was academic research and exploration into collaborative practice. The "Pairings" project began in 2010 at Manchester School of Art with 32 academics from across the UK, working in partnerships developed through day-long speed dating and sharing events. This ongoing research into the nature of collaboration informed our thinking and embedded this not only as a research theme and strength, but also as a catalyst to shared approaches to learning and teaching. This brought greater awareness of the benefits of cross subject co-operation and dialogue. As reflected upon by David Gates, Senior Lecturer at the London Metropolitan University and academic collaborator in the Pairings project,

'To be able to give and take back, listen and share. Trying to understand someone else, trying to find a way in and drop in on the beat, I that space of trust and of knowing-ness crossing, something almost intangible might happen. A sometime humbling yet enabling sensation that someone trusts you with something that is special to them: their voice, their view. Being nudged into un-familiar territory the specialness is in the process, the experience and the journey. In all the exchange, the talk, the doing, new things are forged.' (Groppel-Wegener, 2010)

\subsection{LEARNING ABOUT COLLABORATION}

Learning from Pairings has greatly informed the methodology employed in generating collaborative teams to deliver Unit X. Prior to introduction in 2012, staff were invited to take part in mapping their responses to the unit X project for the year, entitled 'Interrogating Manchester'.

The event involved open discussion of approaches and thinking, followed by intensive speed-dating to identify sympathetic and coherent partnerships. This resulted in the formation of teams to take further ideas for working together, and provided a structure to identify complementary teaching and learning approaches and interests. Interestingly, although this was repeated before the 2013 planning, the introduction of new partners into the mix was less effective and additional events were necessary to re-frame the teams for 2014.

For the second level of the unit a slightly different approach was taken, with the emphasis on students engaging with a professional model of practice. An audit of professional opportunities, staff practice and research across programmes was undertaken, revealing fascinating correlations across the School falling under four broad categories. These became the 'colleges' into which in dividual students opted to study. The learning and teaching model in each college was tailored and delivered by the staff whose expertise and research was aligned with the identified context and approach.Therefore once again seeing both staff and students engaged in collaboration.

College 1, 'Pass it on' saw students placed with Schools, Community Groups and our research centre in Arts for Health.

College 2, 'The Client' was for collaborators working as consultancy groups on projects for external Partners such as DKNY, the Manchester International Festival and the design group Designers Republic.

College 3, 'Blue Sky Thinking' presented proposals to the Manchester City Council and the Museum of Science and Industry, proposing new thinking and models for use of the public realm. 
College 4 'Make it-Sell it' involved generating products for the Craft and Design marketplace, in response to the digital archive of National Trust Collections, developing content for a Zine and book Fair or producing film and animations for a live performance by an emerging musician.

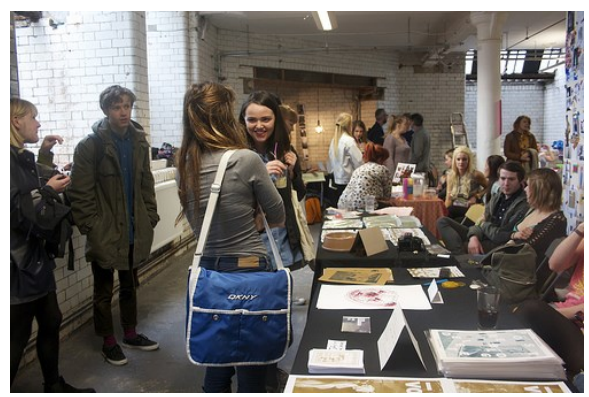

Figure 6: Zine Fair

\subsection{SELF REALISATION}

Through Unit X what staff and students are now unknowingly demonstrating and comprehending are the necessary 'soft transferable' skills they have acquired and are now utilising. Highly employable skills in negotiation, decision making, people skills, project management skills, an ability to creatively collaborate in teams. Interestingly, the valuing of these skills is challenging the intrinsic value of 'subject' skills, which arguably are predominantly based around the crafting of artefacts and work. What has emerged is that students and staff have come to the realization that they have skills, which they did not realize they possessed. They have nurtured high-level project management skills, an ability to be empathetic. What becomes fascinating is what we value and what type of practitioners/theorists we are producing. When assessing work why shouldn't criteria based on project management be as highly valued as criteria for producing a 'body' of work. Positively, students have learnt from one another's disciplines and reflected it back upon their own, thus leading to new forms of practice.

\subsection{CHALLENGING CRITERIA, WHERE'S THE WORK?}

Unit $\mathrm{X}$ has challenging criteria, focussing on employability skills around crossdisciplinary teamwork, contextual and interdisciplinary awareness, the development of a body of work driven by external partners and external opportunities and the ability to communicate practice to an informed audience.

Outputs can therefore be negotiated by the cross programme teams and particularly for the first year students may not reflect the 'specialism' of every individual. The resulting body of work is a collective response, with each member contributing to the whole their skills and expertise, however these may be in project management, negotiation, presentation or mediation, not always subject linked technical skills and knowledge.

Usefully, Wenger in 'Communities of Practice' discusses a social theory of learning in offering a conceptual framework for how we understand and enable collaborative learning and in doing so gives us some principles to work towards. He alerts us to the knowledge that social learning and social participation heightens learning. He stresses that within a community:

'the learning that is most personally transformative turns out to be the learning that involves membership in these communities of practice. ' (Wenger, 1998) 
Throughout unit X the balance between what is taught and un-taught are central.

'teaching does not cause learning: what ends up being learned may or may not be what is taught, or more generally what the institutional organization of instruction intended. Learning is an emergent, on going process, which may use teaching as one of its many structuring resources...what matters is the interaction of the planned and the emergent-that is, the ability of teaching and learning to interact so as to become structuring resources for each other. (Wenger, 1998)

The organization and structure of unit X is on a large scale, (in 2012 there were 430 first year students involved, in 2013 there are 680 first years and 420 second year students) and therefore there is a need for a strong framework to allow the different collaborative models to emerge and flourish. Interestingly, each teaching group developed their own models of practice and it appears that by offering a framework of learning, as Wenger describes 'an architecture for learning' is formed (Wenger 1998). These groups given a foundation, which may have consisted of a series of workshops/activities as the groundings of collaboration, appeared to be in a stronger position.

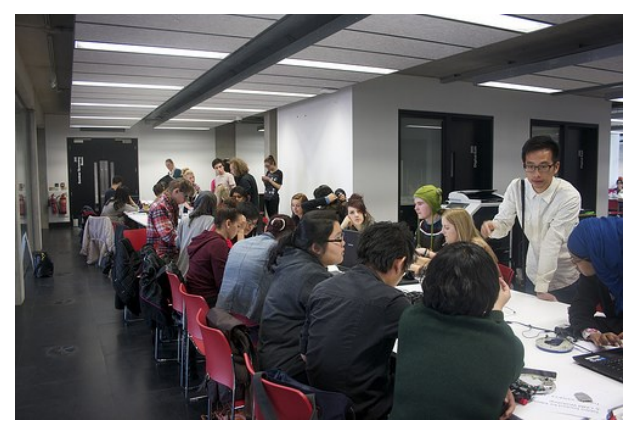

Figure 7: Studio workshop - developing digital throwies.

'Unit X has been a completely different experience in terms of both group work and design. I think it gave us a broader understanding of how things work.......I truly enjoyed most of the workshops as they showed us simple ways to communicate our ideas in a completely new ways.' (student reflective blog)

Unit X poses new challenges in areas of organization, spatial considerations, logistics, assessment, and highlights the need for cross-university systems to be flexible and adaptable. Increasingly unit X means that we have to look to new ways of dealing with this. The use of social media and new technologies has also permitted us to deal with many of the challenges. The notion of space, and place is played out during unit X. Where students have to find new ways to work; they are no longer tied to the security of the space offered within the university. 


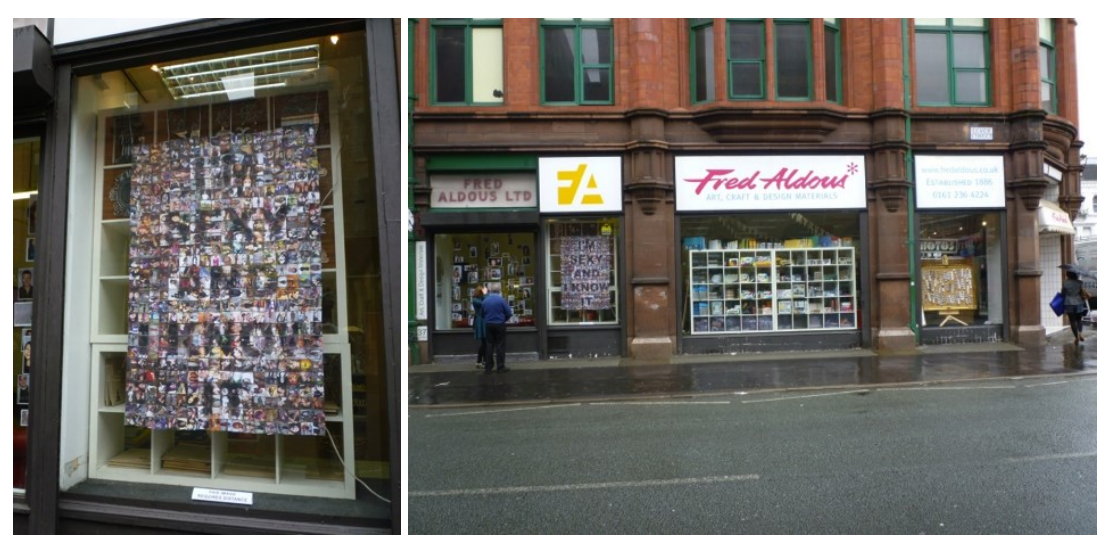

Figure 8 \& 9: Student negotiated Shop window showcase
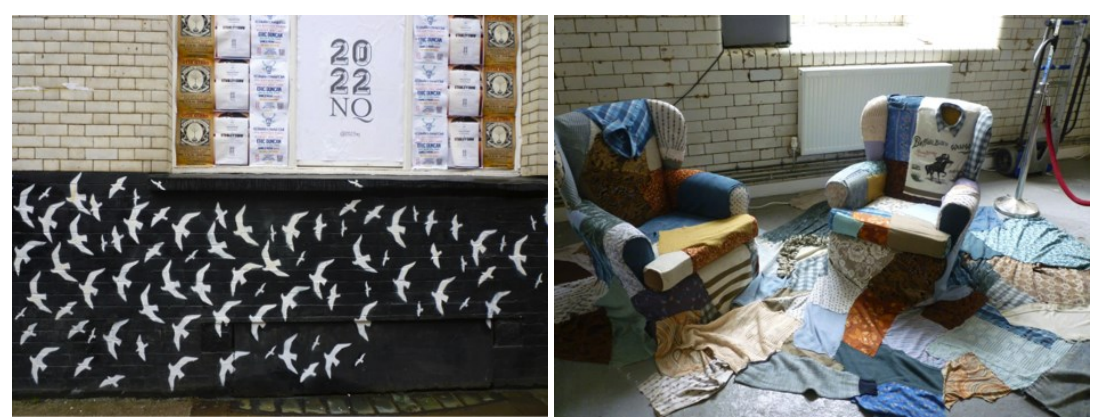

Figure $10 \& 11$ : Installations in basement space in city centre

In Unit X we purposefully take the students out into the city and their work takes part in the city. It is a form of situated learning. Students have started to use new methodologies in their practice; some became video ethnographers, situationists as they went on derives through the city. The richness of these research methodologies and methods introduced students to a range of approaches and enabled them to understand the complexity and richness of their own research.

\subsection{REFLECTION}

In 'Institutional Strategies to Link Teaching and Research', where Jenkins developed a typology of the nexus between research and teaching he argues that teaching can be researched based in the sense that:

the curriculum is largely designed around inquiry-based activities, rather than on the acquisition of subject content;

the experiences of staff in processes of inquiry are highly integrated into the student learning activities;

the divisions of roles between teacher and student are minimised;

the scope for two-way interactions between research and teaching is deliberately exploited. (Jenkins \& Healey, 2005)

However, it can also be research informed in the sense that:

'it draws consciously on systematic inquiry into the teaching and learning process itself.' (Jenkins \& Healey, 2005) 
From further reflection we need to be able exploit the above to help us in developing a typology for Unit X. We also need to reflect further on the challenges we faced during Unit X. Those challenges need to be confronted, and as Brew describes:

... where the distinctions between teaching, learning and research break down as both teachers and students explore and share the issues that confront them. Yet this means facing up to elements of the academic environment that work against the integration of academics and students (Brew, 2006).

Or perhaps:

'a different kind of university' (Brew, 2006 ).

Unit X is rich, risky, dramatic and edgy. Respective disciplines and behaviours are challenged. Students appeared to have very different skills sets and attitudes to learning. Does a contemporary art student possess a different set to a fashion student? Unit X once again challenges this and makes it real and exposes the differences.

'Unit x has been a personal journey for me. For some it may have been just a simple project were they learn a few things and gain experience. However, for me, Unit $x$ has changed my views, the way I think, even my future career.' (Year 2 student Blog)

\subsection{INTANGIBLE LEARNING - A CONCLUSION?}

As unit $\mathrm{X}$ progresses it becomes essential that staff need to take on new roles and centrally question what an academic is. The work of Boud and Miller (1996) help us to reflect upon this. They take the traditional term of animation, 'bringing to life', but apply it within a pedagogic context where staff should take on the active role of being 'animators' with the need to inspire and vivify as a core part of their teaching and research. What we are seeing is staff increasingly becoming colearners and act as producers or co-producers of learning. The animator's role becomes even more paramount within experiential environments: 'we see the function of animators to be that of acting with learners, or with others, in situations where learning is an aspect of what is occurring, to assist them to work with their experience' (Boud \& Miller, 1996). Again, this shift is challenging. Staff feel uncomfortable in being able to assess where the learning is taking place. It can feel intangible.

Within Unit X we explored the notion of community, co-operation and collaboration where learning is seen as a social practice. If we tie this to the idea that learning is part of the social constructivist understanding we begin to understand the model. The work is based around situational learning where the student proposes that learning involved as a process of engagement in a 'community of practice'. We endeavour to suggest to students and staff that learning is a social activity and comes from our daily life. The project aims to establish these principles and as the programme developed students became part of the situation and engaged in further exchange learning more about each other. Here again we refer to a form of experiential learning. Students develop relationships over a period of time.

According to Wenger (1998), a community of practice defines itself along three dimensions:

What it is about - its joint enterprise as understood and continually renegotiated by its members.

How it functions - mutual engagement that bind members together into a social entity. 
What capability it has produced - the shared repertoire of communal resources (routines, sensibilities, artifacts, vocabulary, styles, etc.) that members have developed over time. (Wenger 1999)

These are words, written by first year students in their reflective BLOG submission are typical of the reflections made by others in the Unit.

'Towards the end however, if and when the project changed, we had come together as a group and we all knew each-others strengths so that we could figure out a solution to the problem as quickly as we could.' (Student blog)

'Group tasks are hard and difficult but I have learnt so much... In my group I have 3 film students, 2 fashion and 2 other textile students... Usually with a project you're on your own and your ideas are stuck in your head and you can get lost within it all but having a group to vent your ideas too was so good and helpful. I also learnt how to find common ground with ideas.' (Student blog)

In spring 2013 the 680 students in Level 1 gave feedback ranging from $1.8-4.0$ ( Where 1 is poor and 5 is high.). The pass rate was 98\%. At level 2420 student satisfaction feedback for the colleges ranged from $3.96-4.0$ with a pass rate also of $98 \%$. Clearly Level 4 is a challenging and scary experience, however the response at level 5 indicated a satisfaction level and success rate that is very high. Interviews with students indicate the learning from Level 4 is crucial to the success and satisfaction at level 5 , however detailed statistical and in-depth interrogation of this assertion is yet to be undertaken.

\subsection{THE EFFECT?}

The idea of collaboration really rocked the foundations of subject specificity. Unit $\mathrm{X}$ enabled us to reflect back upon and question what is a subject. These tensions and questions have become ongoing debates. Ultimately, when discussing this with staff we discussed what is innovation. To be truly innovative it means that some things will 'fail'. This in turn questions the value of failure in the creative process, the need to test, trial, fail, succeed, and move on. By not taking any risks we will not be able to understand and develop further. It may for some be seen as a step too far in many ways, however, not taking such giant steps would never allow us to address true innovation. By going to an extreme it has enabled us to really fundamentally question the good, the bad and the unthinkable.

The next phase? A review of Unit X to reflect upon what works, what needs improvement and in the spirit of true creativity what we still need to test. 2014 will see the introduction of Unit X for Final year students, where individuals will negotiate their own professional model for their final output. It will be interesting to see what results; a graduate show with a broader scope; conference; social enterprise; publication; design studio or artists collective showcasing their particular model for their chosen professional arena. The students will no doubt show us what this could be.

\section{TO CONCLUDE}

This paper has highlighted design collaborations through the impact of three drivers: collaboration, interdisciplinary practice and co-operation. It hightlighted this from several aspects, the art school's ethos and direction, a physical resource, and a radical new curricula. We are however cognisant of: 
'Communities of practice do not usually require heavy institutional infrastructures, but their members do need time and space to collaborate. They do not require much management, but they can use leadership. They self-organize, but they flourish when their learning fits with their organizational environment. The art is to help such communities find resources and connections without overwhelming them with organizational meddling. This need for balance reflects the following paradox: No community can fully design the learning of another; but conversely no community can fully design its own learning.' (The systems Thinker, 1998)

We ultimately realize that we have a long way to travel and to learn from and that we are realistic in that:

'learning cannot be designed. Ultimately, it belongs to the realm of experience and practice. It follows the negotiation of meaning; it moves on its own terms. It slips through the cracks; it creates its own cracks. Learning happens, design or no design. (Wenger 1998)

however, we hope we are getting there and have provided a collaborative design environment through engaging with the good, the bad and the unthinkable!

\section{REFERENCES}

Brew, A. (2006). Research and teaching, beyond the divide. Palgrave Macmillan. 3,4.

Boud,J. and Miller,N. (1996). Working with Experience, Animated Learning Routledge Chapman \& Hall, 7.

Design Commission. (2011). Restarting Britain, Design Education and Growth. Design Commission Report, 7,15.

Groppel-Wegener.A. (2010). Pairings - A conversation Exploring Collaborative Creative practice. Blurb, 90.

Jenkins A and Healey M (2005). Institutional Strategies to Link Teaching and Research, York: The Higher Education Academy, 22.

Wenger, E. (1998, 1999). Communities of Practice. Cambridge University Press, 6, $267,73-84 \& 225$.

Schleicher (2010) The Case for $21^{\text {st }}$ century learning. Retrieved from: http://www.oecd.org/general/thecasefor21st-centurylearning.htm

The Systems Thinker. (June1998) Communities of practice, learning as a social system. Retrieved from http://www.co-i-l.com/coil/knowledgegarden/cop/lss.shtml

I DON'T KNOW WHERE I'M GOING BUT I WANT TO BE THERE The expanding field of Graphic Design Symposium. Retrieved from 
http://www.motimuseum.nl/en/events/calendar/symposium-18-december$2010-/ 609$ 